WEREIVED

ION 251995

\section{USTI}

The submited manuseript has been authored by a contractor of the L. S. Govertimen under contract No. W-31.109ENG.38. Accordingly, the U.S. Government retains nonexclusive, raystryltee liense to pubish or reproduce the published form of this contribution. or allow others to do $\$ 0$, for
U.S. Government purposes.

\title{
Current Status of ATLAS and Proposed Expansion to an Exotic Beam Facility
}

G. P. Zinkann, P. Billquist, J. Bogaty, B. Clifft, F. Munson, K. Nakagawa, J. Noien, R. Pardo, K. W. Shepard, J. Specht, A. Sutherland, B. Tieman, and I. Tilbrook

Argonne National Laboratory

\begin{abstract}
The Argonne Tandem Linear Accelerator System (ATLAS) has been operating on a twenty-four hour, seven days a week schedule since the beginning of Fiscal Year 1994. Twentysix different ion species ran during this period in 71 separate experiments. During the past year, there have been many projects undertaken to improve operation efficiency and upgrade various accelerator systems. There is also a new ECR ion source construction project underway. This paper covers, linac operation and new tuning techniques, the second generation ECR source construction project, the refrigerator system upgrade, an upgrade to the control system. Also described is a future expansion of ATLAS as an Exotic Beam Facility. ATLAS is a world class heavy ion accelerator with an estimated value of approximately $\$ 80$ million. A concept that would utilize ATLAS as the foundation for a facility to generate and accelerate radioactive beams is briefly discussed.
\end{abstract}

\section{INTRODUCTION}

ATLAS is a niobium superconducting heavy-ion accelerator at Argonne National Laboratory. It is a tool for research in nuclear physics, atomic physics, and occasionally some 


\section{DISCLAIMER}

Portions of this document may be illegible in electronic image products. Images are produced from the best available original document. 
other areas of science. The accelerator is a two-fold system consisting of an injector followed by a superconducting linac. There are two injectors available, a $9 \mathrm{MV}$ electrostatic accelerator with a negative-ion source (TANDEM) and a positive-ion injector (PII). PII is an ECR source on a high voltage platform coupled with a superconducting low-velocity linac. ATLAS is capable of delivering beam to three separate target areas. Figure 1 is a floor plan of ATLAS.

\section{Operating History}

ATLAS has been in operation, in various configurations, since 1978. The accelerator originally consisted of a $9 \mathrm{MV}$ tandem and twenty-four split-ring superconducting resonators in four cryostat modules. In 1985 a section of three more cryostats, for a total of forty-two resonators, and a new target hall were added. In the summer of 1992 the PII injector consisting of 18 interdigital superconducting resonators in 3 cryostats became operational. At present, the total number of niobium superconducting resonant structures on-line is sixty-four.

In the beginning of fiscal year (FY) 1994, ATLAS started a 24 hour, seven days a week schedule. The goal of this change was to increase the amount of beam time available for research. This was accomplished in two ways: first, by having more staffed hours per week, and secondly, by not turning the machine off on the weekends. Not shutting down for the weekends is beneficial in several respects:

1. The operating efficiency was improved.

2. There was a reduction in down-time caused by electronic failures.

3. The start-up time previously required on Monday mornings was eliminated.

Table 1 shows statistics for operating hours for FY 1994 and for the first 10 months of FY 1995.

\section{DISCLAIMER}

\footnotetext{
This report was prepared as an account of work sponsored by an agency of the United States Government. Neither the United States Government nor any agency thereof, nor any of their employees, makes any warranty, express or implied, or assumes any legal liability or responsibility for the accuracy, completeness, or usefulness of any information, apparatus, product, or process disclosed, or represents that its use would not infringe privately owned rights. Reference herein to any specific commercial product, process, or service by trade name, trademark, manufacturer, or otherwise does not necessarily constitute or imply its endorsement, recommendation, or favoring by the United States Government or any agency thereof. The views and opinions of authors expressed herein do not necessarily state or reflect those of the United States Government or any agency thereof.
} 


\section{Machine Development}

There have been some significant developments in the area of beam production at ATLAS. In the ECR source, direct plasma sputtering was observed during laser ablation studies'. The sputter method involves placing a negatively biased solid sample just outside the ECR plasma. Plasma ions, supplied by the support gas, accelerate toward the sample, impact upon its surface, and sputter solid material into the plasma. This technique proved to be very valuable in a ${ }^{48} \mathrm{Ca}$ run. Using the ECR sputter method, a $20 \%$ enriched sample of ${ }^{48} \mathrm{Ca}$ was used to deliver 1-2 pnA on target, with a source target consumption rate of $100 \mu \mathrm{gm} / \mathrm{hr}$. A second significant ion beam development involved the negative ion source and the Tandem accelerator. The measurement of the ${ }^{18} \mathrm{~F}(p, \alpha){ }^{15} \mathrm{O}$ reaction was carried out with a ${ }^{18} \mathrm{~F}$ beam of a few ppA at ATLAS $^{2}$. Because of the relatively long half-life of ${ }^{18} \mathrm{~F}\left(T_{1 / 2}=100 \mathrm{~min}\right.$. $)$ it was possible to use a two-step procedure for the beam production. ${ }^{18} \mathrm{~F}$ is generated at the medical cyclotron of the University of Wisconsin. Chemical processing was done at the University, details of which will be published later ${ }^{3}$. The end product is a copper cathode with ${ }^{18} \mathrm{~F}$ ready for insertion into a National Electrostatics Corp. SNICS ion source. The cathode is transported by air to Argonne National Laboratory and installed into the source. With an activity at the end of the chemical process of $530 \mathrm{mCi}$, the experiment starting activity, after 2 hours ( transportation time), was 250 $\mathrm{mCi}$, corresponding to a total number of ${ }^{18} \mathrm{~F}$ atoms of $8.8^{*} 10^{13}$. Figure 2 displays the results of this experiment.

In FY 1994 there was a total of 71 separate experiments run with a total of 26 different ion species. Similarly, as of August FY 1995, there were 48 separate experiments run with a total of 25 different ion species. Because of the number of different experiments, which require separate accelerator tunes, and because of the fact that the charge to mass ratios vary widely, a new tuning technique is being developed. A library of tunes is kept. When beams are tuned with the same $q / m$ as a previous run, the appropriate archived tune table is loaded into the 
accelerator tables. When there is not an exact match however, the most similar tune is loaded, then the resonator field levels are scaled to match the velocity profile of a previous tune with a slightly different $q / \mathrm{m}$. There was a technical challenge with this technique. Due to the physical layout of ATLAS the three accelerator sections are in three different rooms. We found that because of small differences in the time-of-arrival (TOA) at the entrance of each accelerating section, the correct velocity profile through a given section was not properly preserved. To fix this problem a TOA phase monitor was installed. ${ }^{4}$ Along with the TOA, a modification to the Master Oscillator System was made. The Master Oscillator modification gives each section of the accelerator an its own phase shifter that changes the phase of all resonators in that section independently of the other sections. The new tuning method records the TOA phase of the archived tune and then matches that phase, using the independent phase shifter, for the new scaled tune. The hardware required is installed in all three sections but at the present time, the electronics necessary to read the phase is only installed in the Pll section. The use of this method in PII has worked exceedingly well and the translation to the other parts of the machine is expected to work as well.

Figures $3 \& 4$ demonstrates the number of different ion species and the percentage of time each species was run. It is clear from these charts that most demand is for beams heavier than mass 58.

\section{Linac Performance}

The resonator performance necessary to achieve so many hours of beam on target must be very reliable. Resonator levels are set conservatively so as not to cause unacceptable down time. Therefore, the operating levels given below are not the maximum achievable fields, but rather the daily operating levels. For the PII interdigital structures the average accelerating field level is $3.65 \mathrm{MV} / \mathrm{m}$. For the low beta $(0.06 \mathrm{c})$ structure the average accelerating field level is $3.20 \mathrm{MV} / \mathrm{m}$, the high beta $(0.1 \mathrm{c})$ structures the average is $2.90 \mathrm{MV} / \mathrm{m}$. Given the above 
accelerating fields, for an optimum velocity particle, the total linac voltage is $42.3 \mathrm{MV}$. Figure 3 shows a graph of ion mass verses beam energies typically available at ATLAS. The ATLAS accelerator has excellent beam quality. Typical longitudinal emittances of 10-20p keV-nsec permits beam timing resolution in the 100 psec range simultaneously with energy resolution of $\delta E / E<10^{-3}$. ATLAS can presently accelerate ions of charge state $q / m>0.15$.

\section{New ECR Source Construction}

ATLAS supports research programs in many areas of nuclear physics. The user demand has increased considerably since the completion of PII with its capability for delivering high quality beams from the entire periodic table. Many of the programs at ATLAS would benefit greatly from the capabilities that will be made possible with the addition of a second generation ECR ion source. Such an ion source is now the highest priority accelerator improvement project at ATLAS.

The second ECR source is a collaborative project between Argonne National Laboratory and Lawrence Berkeley Laboratory. The source is an evolutionary design based on the highly successful $14 \mathrm{Ghz}$ Advanced ECR ion source ${ }^{5,6}$ now in operation at the LBL 88 inch Cyclotron Laboratory. Some improvements include enhancements in the solenoid and hexapole magnetic fields. These changes were made because of the recent understanding that a high mirror-ratio solenoid field design and a strong hexapole field are important parameters in the performance of high-charge state ECR ion sources. The new source will also possess an all aluminum hexapole housing and other components to make use of the large secondary electron yield from aluminum oxide.

With the present ECR ion source, the charge state distribution is such that it is necessary to strip heavy beams, such as uranium and lead, to reach $6 \mathrm{MeV}$ per nucleon with the ATLAS linac. Existing second generation ECR sources are producing analyzed currents of 1.5 2 euA of $34+$ bismuth and lead ions. Figure 6 compares the charge state distribution, for 
uranium, achieved with the LBL AERC ion source verses the first generation PII ECR ion source. With such high charge states available from the new source, even the heaviest beams, such as uranium, can be accelerated to energies above the Coulomb barrier without subsequent stripping. This new capability will result in three important benefits. Both beam emittance and stability would be improved, beam intensity delivered on target will be increased, and the beam intensity will not be dependent on stripper foil lifetime.

All phases of construction on the new ECR source project are moving along at a good pace. The new building is expected to be occupied by November 1995. Figure 7 shows the status of the construction on August 22,1995 . The source design is complete, and construction of the source components is approximately $70 \%$ complete. Initial source operation is scheduled for the late spring of 1996. The new source is expected to be used with ATLAS in 1997.

\section{Refrigerator Improvements}

The majority of the 693 hours of scheduled down time this year was for the installation of two wet engine expanders on the helium refrigeration system. The wet engines were added to the output of two, model $2800 \mathrm{CTI}$ refrigerators, replacing the Joule-Thomson valves. The goal of this upgrade was to increase the refrigerator efficiency and capacity. Before the installation of the wet engines, the ratio of the power input $(300 \mathrm{~kW})$ to the cooling power output $(300 \mathrm{~W})$ was 1000 Watts/Watt. Preliminary measurements made after the installation indicate an improvement of that ratio depending on the quantity of compressed helium gas delivered to the refrigerator (power input). After the upgrade, the ratio was measure to be 822 Watts $/$ Watt. However, with a lower power input of $250 \mathrm{~kW}$, the resulting power ratio is 718 Watts Watt. There are still more ways to improve these figures. Further improvement to the refrigerator efficiency will be investigated. Figure 8 shows one of the two wet engines. 


\section{Control System Upgrades}

The ATLAS control system is presently in the third and final phase of a major upgrade project. Before the start of the computer upgrade project, the control and monitoring of the accelerator was accomplished with three DEC PDP-11 computer systems. The operating system for the PDP-11 was RSX-11. All the software was written in-house, and subsequently had to be supported by only a single in-house staff member. A CAMAC serial highway subsystem was used as the primary interface between the computer systems and the various accelerator components. Control of the accelerator was from the control room, although the operator interfaces included a variety of touch screens, monitors, terminals, knobs, keypads, and switches that were geographically removed from each other. Having a spread out variety of controls proved to be very cumbersome and confusing.

The upgrade will replace all the PDP-11 computers with a DEC MicroVAX using the VMS operating system. Graphic workstations are provided, which are capable of using the " $X$ " windowing system as an operator interface. Control and monitoring, from various locations throughout the machine, are accomplished using " $X$ " terminals, or PCs used as " $X$ " terminal emulators. Figure 9 shows a PC terminal emulator at the entrance of the PII linac.

All the systems are linked by Ethernet into a local area network configuration. The new system uses a commercial software package marketed under the name "Vsystem" by Vista Control Systems, Inc. Due to a large investment in CAMAC components the CAMAC VO subsystem has been retained.

The process of removing tasks from the PDP-11s and replacing them with the VAX control system has been done mostly while the machine is in operation. Many painful steps had to be taken to insure that the operation of the machine was not compromised. Indeed, some of the processes have proved to be very difficult to remove from the last remaining PDP-11. So the few remaining tasks are being worked on, and soon the final phase will be complete. When 
this is done, the MicroVAX will be replaced by a machine using the latest RISC technology, thus completing all the goals of the upgrade project.

As a result of this upgrade, virtually all operator interface with the accelerator is accomplished from two workstations in the control room. Figure 10 shows the two workstations and the multiple screen capabilities.

\section{Exotic Beam Facility}

There is much enthusiasm in the nuclear physics community for the opportunity to study reactions and spectroscopy using radioactive beams. These opportunities could be provided by an advanced, high intensity accelerated radioactive beam facility based on the isotope-separator on-line (ISOL) method. There are recent reports on this subject from both North American and European study groups ${ }^{7,8}$. Since ATLAS is an ideal post-accelerator for beams of all nuclei, a group of ANL Physics Division staff and ATLAS outside users have discussed the research possibilities with radioactive beams and prepared a working paper entitled 'Concepts for an Advanced Exotic Beam Facility Based on ATLAS : 9

A schematic layout of a possible facility is shown in Figure 11. The existing ATLAS accelerator and experimental facilities are in the lower part of the figure, and the proposed edition for an Exotic Beam Laboratory is in the upper part. In this new facility, radionuclides are produced by irradiating targets with light ion beams from a normally-conducting drift tube linac. The present plan is for the primary linac and production targets to be located below grade level to assist shielding prompt neutron radiation. Using standard ISOL target ion source techniques the radionuclides are extracted and ionized, mass separated, and then sent either directly to an experimental area for research with ion or atom traps, or sent to a low-charge-state superconducting linac ${ }^{10}$ to be accelerated for injection into ATLAS.

\section{Production Methods}


The basic concept is to use a conventional drift-tube driver linac with $100 \mathrm{~kW}$ beam power available for a variety of light ions as indicated in Figure 12. Also in this figure are specifications for the linac. The driver linac would have a fixed velocity profile, but can accommodate beams of several different ions and charge states and could provide up to $215 \mathrm{MV}$ to acceleration. Fully stripped ions with a $q / m=1 / 2$, such as ${ }^{2} \mathrm{H},{ }^{4} \mathrm{He}$, and ${ }^{12} \mathrm{C}$ will be accelerated to $100 \mathrm{MeV}$ per nucleon. Protons at $100 \mathrm{MeV}$ per nucleon and $300 \mathrm{MeV}^{3} \mathrm{He}$ will also be available. With the method of using deuterons to make neutrons, target heating problems are alleviated for production of neutron-rich radioactive nuclei. Also with this method only a modest linac of $200 \mathrm{MV}$ is required as compared to the $1 \mathrm{GeV}$ proton machine required in several other recent proposals. The driver linac can be used for several other ion species to provide good yields of a wide variety of unstable nuclei. A $30 \mathrm{MV}$ RFQ/Linac injector for $q / \mathrm{m}=1 / 6$ permits the pre-acceleration of heavier beams. These heavy ions will be accelerated through an injector as ${ }^{18} \mathrm{O}^{3+}$ or ${ }^{36} \mathrm{Ar}^{6+}$, stripped at $5 \mathrm{MeV}$ per nucleon to ${ }^{18} \mathrm{O}^{8+}$ and ${ }^{36} \mathrm{Ar}^{16+}$ respectively; then they will be accelerated to $100 \mathrm{MeV}$ per nucleon in the $215 \mathrm{MV}$ driver linac. As for the sources, light ions will be available, in the required intensities, from a conventional multicusp ion source. The heavier ions will require an ECR ion source optimized for very high currents at relatively low charge states. The specifications of this driver linac and its injectors closely match the capabilities of a commercial supplier, AccSys Technology, Inc. in Pleasanton, California.

\section{Production Targets and Ion Sources}

Since the production linac described above can deliver up to $100 \mathrm{~kW}$ of a variety of light heavy-ion beams, the production targets will have to be designed to deal with very high power densities. This is a problem of concern to a number of radioactive beam facilities concepts currently under consideration at various laboratories worldwide. One effective solution to this problem is to decouple the heat dissipation issue from that of nuclide production and release to 
the ion source. This can be accomplished by stopping a deuteron beam in a rotating uranium wheel to produce an intense flux of secondary neutrons to irradiate a second target located behind the wheel. This is just one proposed method. Continued R \& D on high power targets and associated ion sources is important for advanced radioactive beam facilities woridwide.

The production method described in above has been investigated for this facility. Quantitative yields from such a geometry were measured recently by an ANLMSU (Michigan State University) collaboration using low intensity, $200 \mathrm{MeV}$ deuteron beam at the NSCL. Yields of a variety of short-lived fission products, including ${ }^{132} \mathrm{Sn}$, were determined. Figure 13 shows the results of this study. Scaling the measured yields to a $0.5 \mathrm{~mA}$ deuteron beam ahd a 100 $\mathrm{g} / \mathrm{cm}^{2}$ secondary uranium target gives $10^{13}{ }^{132} \mathrm{Sn} / \mathrm{sec}$ produced in the ion source/target system.

\section{Secondary Beam Accelerator}

The secondary beam accelerator is based on the existing ATLAS superconducting linac. This technology can accelerate ions from protons through uranium to the energy range from 6 to $15 \mathrm{MeV}$ per nucleon. For an exotic beam facility, a new $30 \mathrm{MV}$ injector section would be needed to accelerate low charge state (typically $1^{+}$) ions to the energies necessary for stripping to the higher charge states required by the existing ATLAS. The technical challenge in developing the low charge state injector is maintaining excellent beam quality in both longitudinal and transverse phase space.

Figure 14 is a block diagram showing the elements of a possible low-charge state injector linac. The first section of the secondary-beam accelerator consists of a $12 \mathrm{Mhz}$ normalconducting RFQ operating on a high-voltage platform. With the ion source at $100 \mathrm{kV}$ and a 300 $k V$ platform, mass 132 ions, for example, enter the RFQ at a velocity of $0.002 c$. Prebunching with a gridded-gap 4 harmonic buncher is done on the platform. With $1 \mathrm{MV}$ of energy gain in the RFQ and deceleration from the platform, the ions are at velocity $0.004 \mathrm{c}$. This velocity is matched for acceleration by the 24 Mhz linac that follows. 
The second accelerating component is a short linac section covering the velocity range from $0.004 \mathrm{c}$ to $0.008 \mathrm{c}$. To cover this lower velocity regime with superconducting structures requires a small extension of currently working components. One design being studied is a folded coaxial line structure operating at $24 \mathrm{Mhz}$. Such a structure should have mechanical and frequency stability comparable to our present $48 \mathrm{Mhz}$ structures that are operating reliably.

The third section, which constitutes $90 \%$ of the new injector, is a $30 \mathrm{MV}, \mathrm{q} / \mathrm{m}>1 / 70$ superconducting linac. This section is based totally on existing 4-gap superconducting RF structures in operation on the PII injector at ATLAS. Using this technology, the exceptional beam quality available at ATLAS will also be obtained from this new injector. Because of the unique modularity of superconducting structures, the machine velocity profile can be easily changed. The present PII design must be upgraded. Because the beams in this section have 6 times lower $q / \mathrm{m}$ than in PII, but cover the same velocity range, the 8 Tesla superconducting solenoids that are used in PII cannot be used here. For good transverse acceptance, they must be replaced with a stronger focusing element. A preliminary design of a small, high-gradient superconducting quadrupole triplet is complete and a prototype is being constructed. The design goal for this quadrupole is $350 \mathrm{~T} / \mathrm{m}$ over a $3 \mathrm{~cm}$ diameter bore. The same quadrupoles would be used in the 24 Mhz section described above.

\section{Performance}

A worksheet based on measured/scaled yields from the ANL/MSU collaboration is presented in Figure 15. It studies the case of ${ }^{132} \mathrm{Sn}$ from the production target and details the expected efficiencies of various ionization, bunching, acceleration, and stripping stages of the ISOL and secondary beam accelerator to estimate the beam intensities to be expected at the proposed facility. 


\section{Conclusion}

The performance and reliability of ATLAS have been enhanced over the past several years as shown in recent operational statistics. A further enhancement will be realized with the addition of a second ECR ion source, scheduled for operation in 1997.

ATLAS can provide a cost-effective starting point for the construction of an Exotic Beam Facility that can satisfy nearly all the specifications of the benchmark facility discussed in the white paper by the North American Steering Committee for an Isospin Laboratory. We are actively developing the technology required for such a facility.

"This work was supported by the U. S. Department of Energy, Nuclear Physics Division, under contract W-31-109-ENG-38 
1 R. Harkewicz, Invited talk at 12 th Inter. Workshop on ECR Ion Sources, Reken, Japan. April 1995

2 K. E. Rehm, et al.,submitted to Phys. Rev. Lett. August 1995

3 A. D. Roberts et al., Proc. of the 13 th Intern. Conf. on the Application of Accelerators in Research and Industry, Denton TX. 1994, to be published in Nucl. Instr. and Meth. B.

4 J.M. Bogaty and B.E. Clifft, 1995 Particle Accelerator Conf, and Intemational Conf. on High Energy Accelerators, Dallas, TX, May 1-5 1995; Bull. Am. Phys. Soc. 40, 1123 (1995)

5 Z.Q. Xie and C.M. Lyneis, Rev. Sci. Instrum. 65, 2947 (1994)

6 Z.Q. Xie and C.M. Lyneis, Rev. Sci. Instrum. 65, 2947 (1995)

7 The IsoSpin Laboratory, Research Opportunities with Radioactive Beams, LALP report 91-51 (1991)

${ }^{8}$ European Radioactive Beam Facilities Report of NuPECC Study Group (1993)

$\checkmark$ Argonne National Laboratory Physics Division Report, Prepared for the Nuclear Science Advisory Committee (1995)

${ }^{10} \mathrm{~K}$. W. Shepard and J.W. Kim in the Particle Accelerator Conf, and International Conf. on High Energy Accelerators, Dallas, TX, May 1-5 1995. 


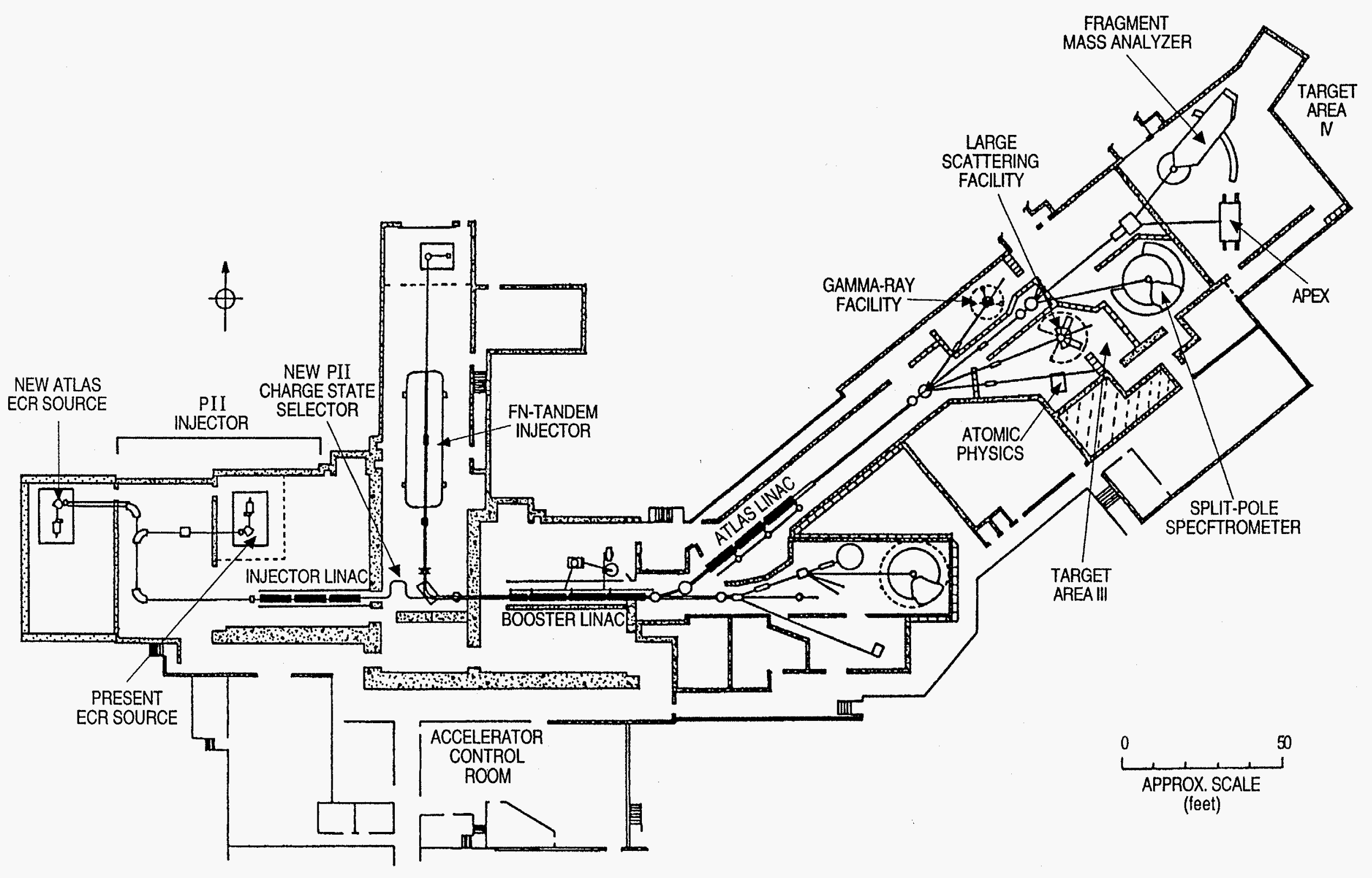

Figure 1. A floor plan of the ATLAS facility. 

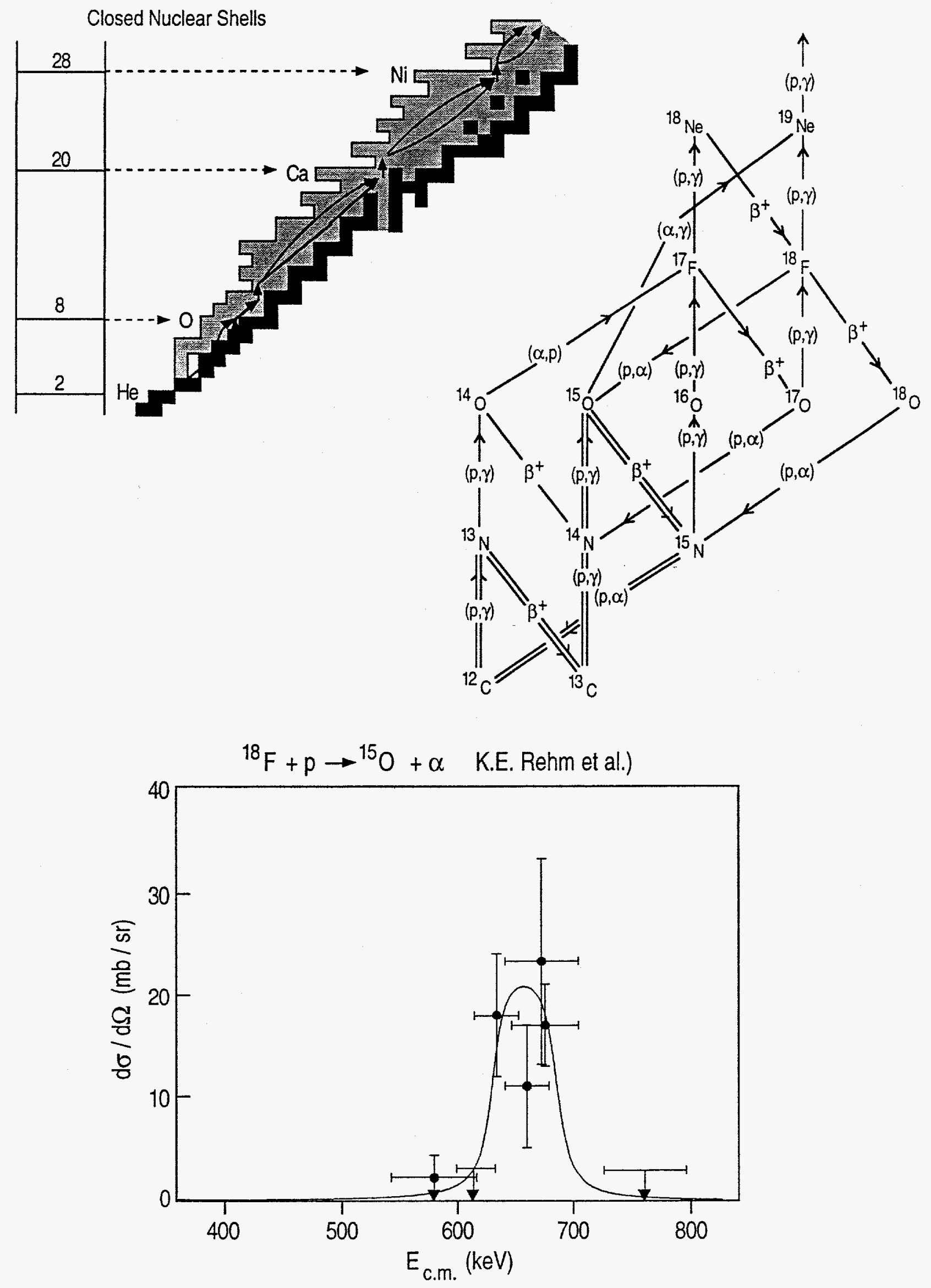

Figure 2. Results of a measurement on the $18 \mathrm{~F}(\mathrm{p}, \alpha) \rightarrow 150$ reaction carried out with a radioactive $18 \mathrm{~F}$ beam produced at the ATLAS facility. 


\section{Beams at ATLAS for Fiscal Year 1994}

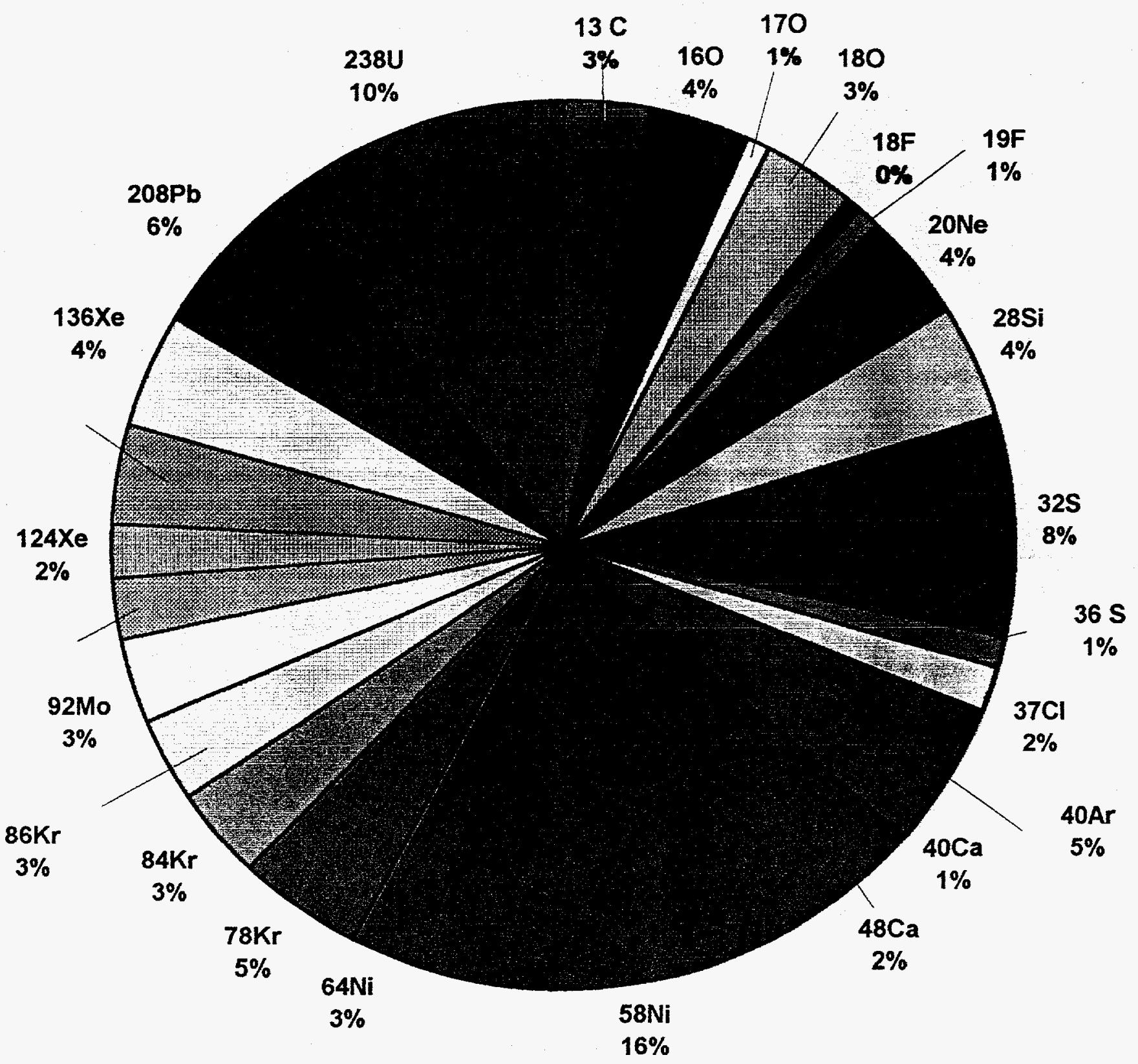

Figure 3 


\section{Beams at ATLAS for Fiscal Year 1995}

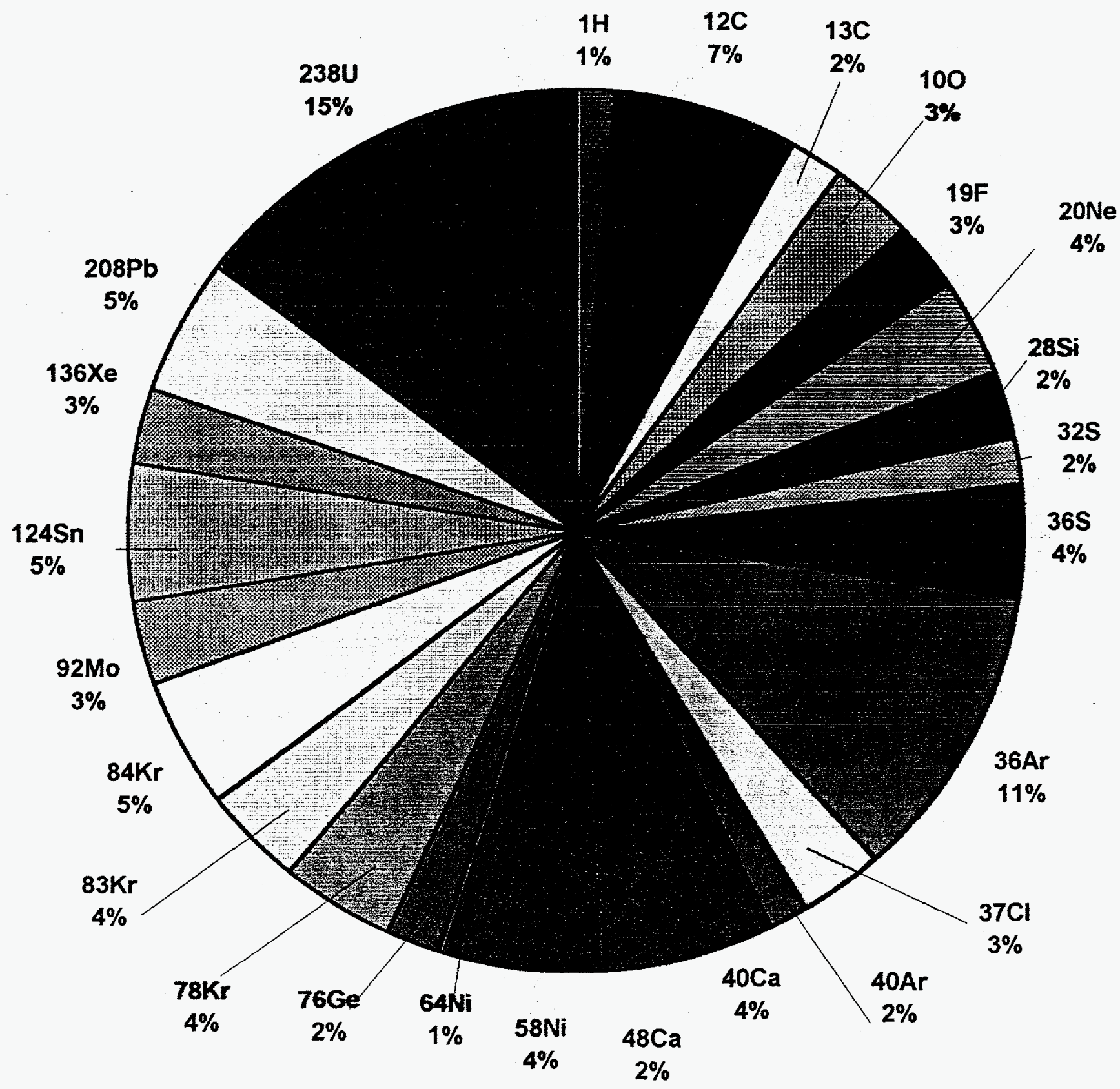

Figure 4 
Fiscal Year 1994

Total Staffed Hours

Total Research Hours

New Experiment Start-up Time

Scheduled Down Time

Unscheduled Down Time

7757.62

5276.60

1273.82

687.69

519.91
Fiscal Year 1995 *

6015.58
3993.67
865.64
693.40
462.87

Fiscal Year starts October 1

* These hours are valid through August 1995. (a 10 month period)

Table 1 


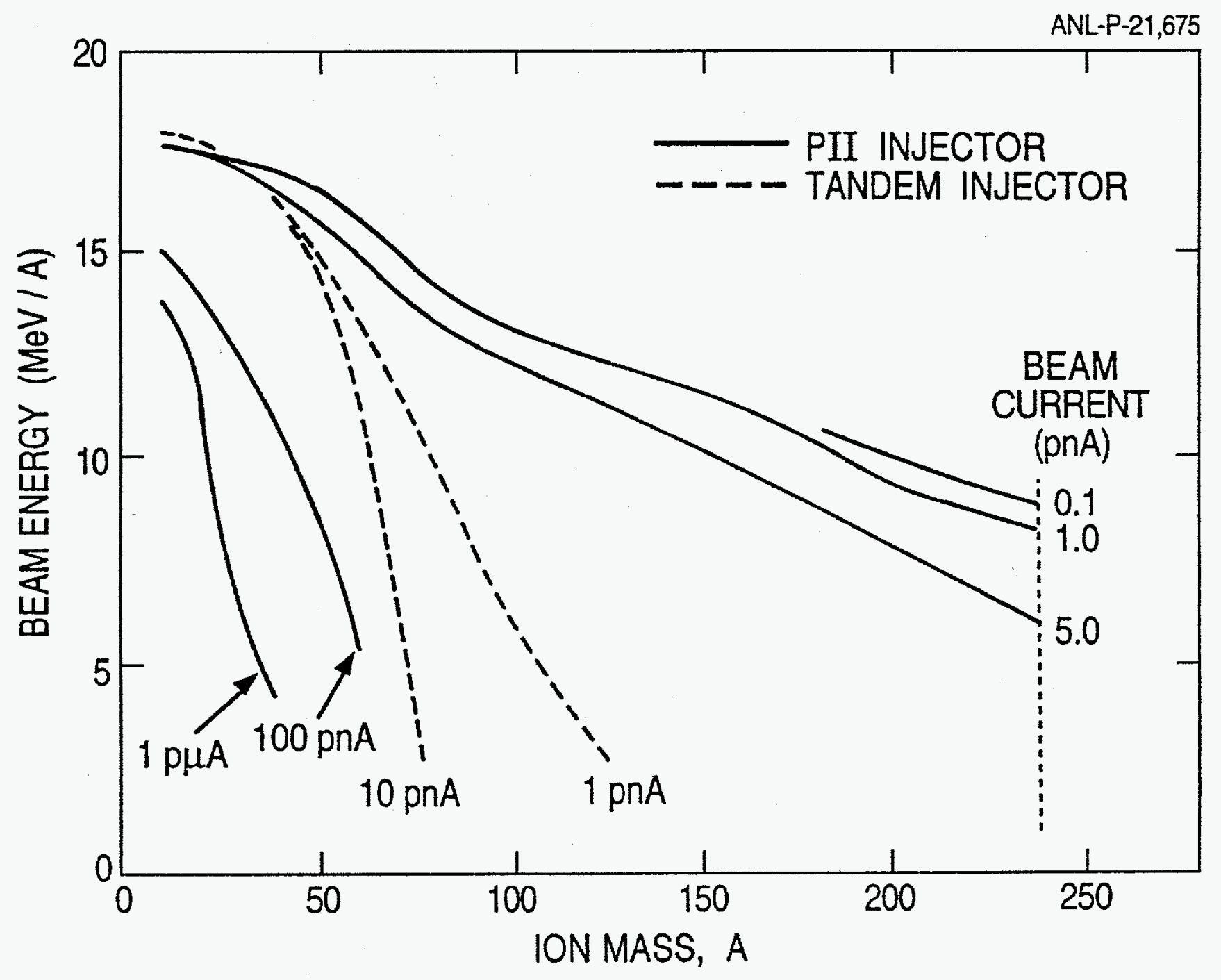

Figure 5. Typical beam energy and intensity presently available at ATLAS. 


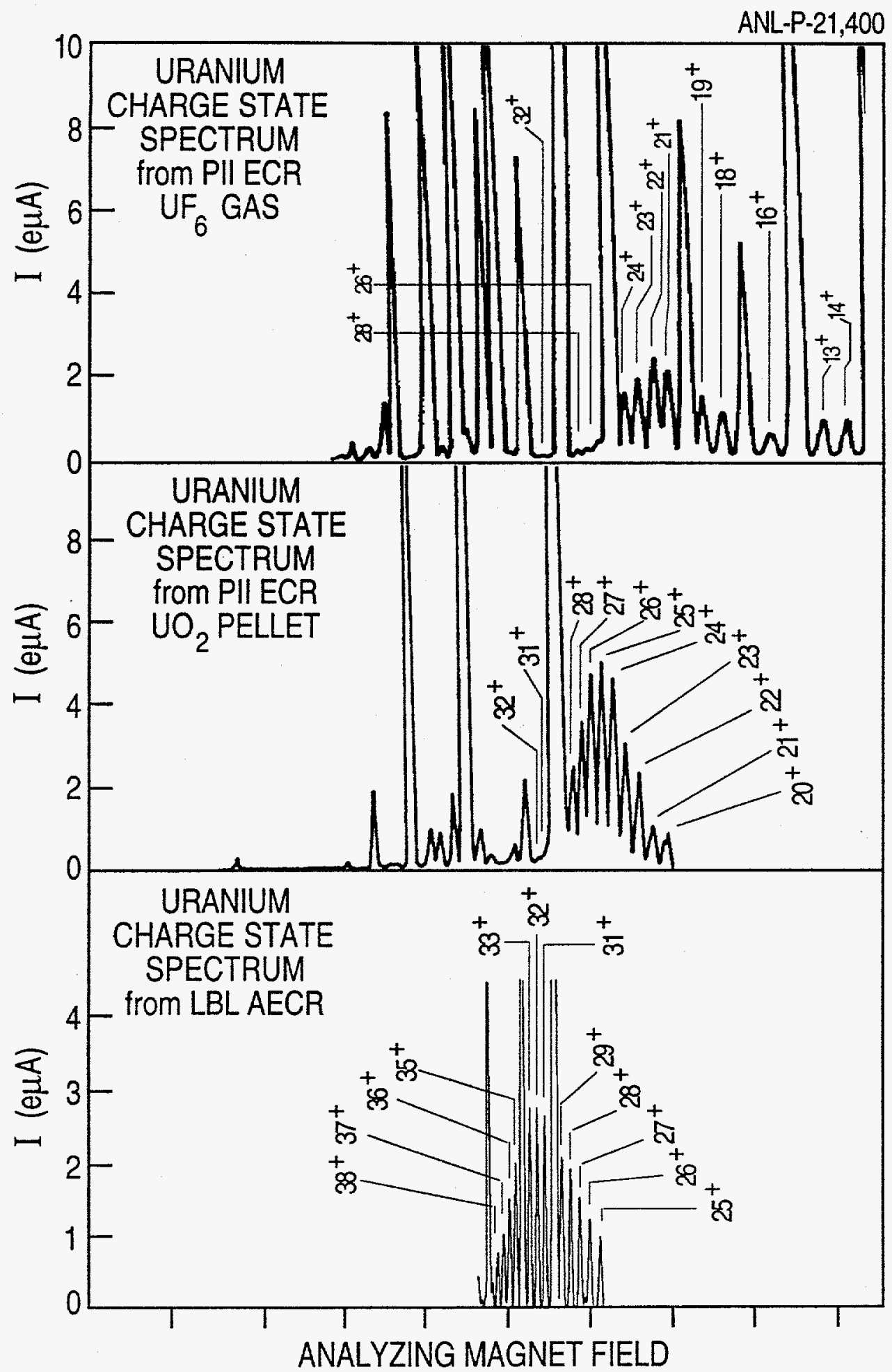

Figure 6. A comparison of the LBL ACER Source and the first generation ANL ECR source for uranium. 


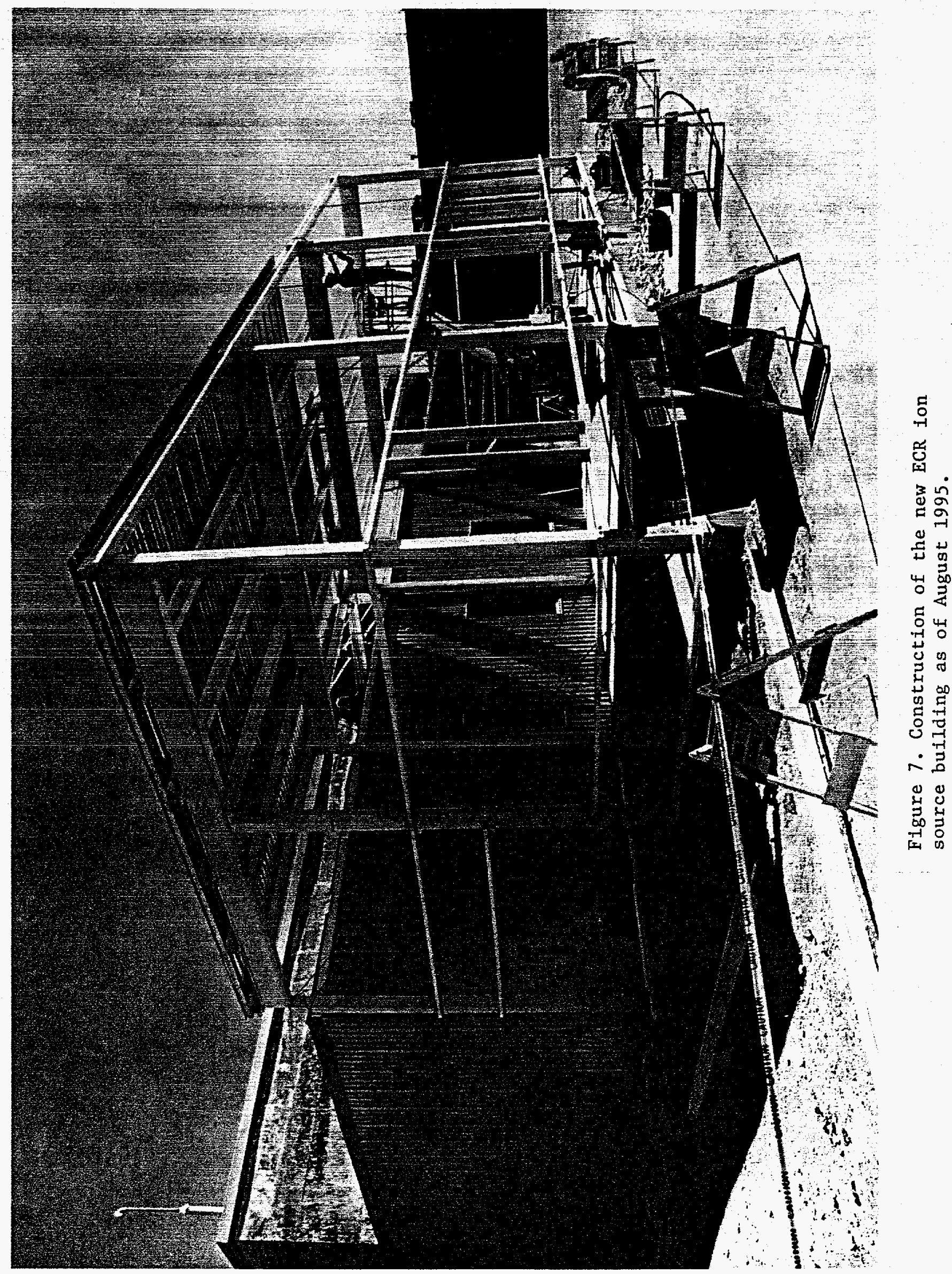




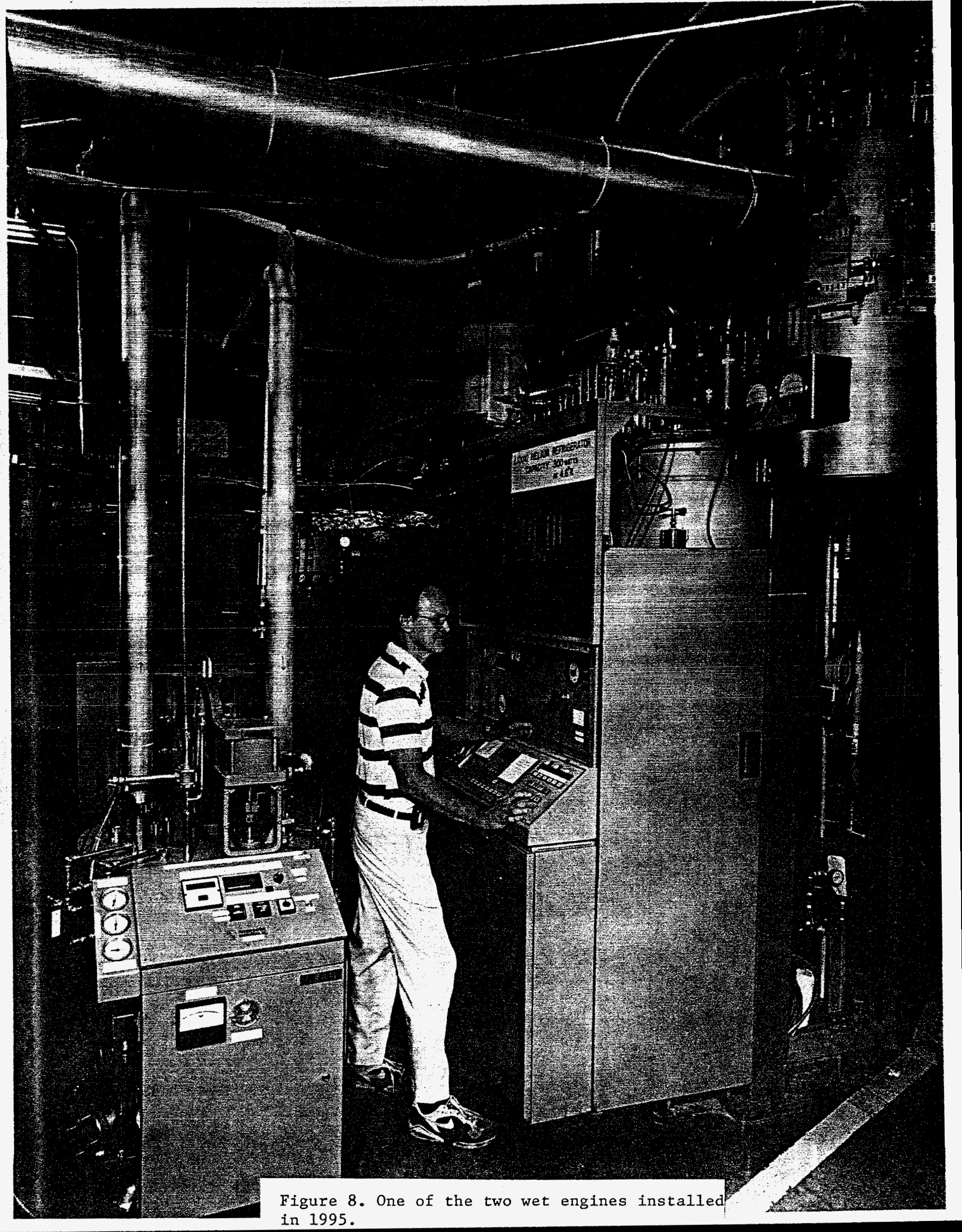




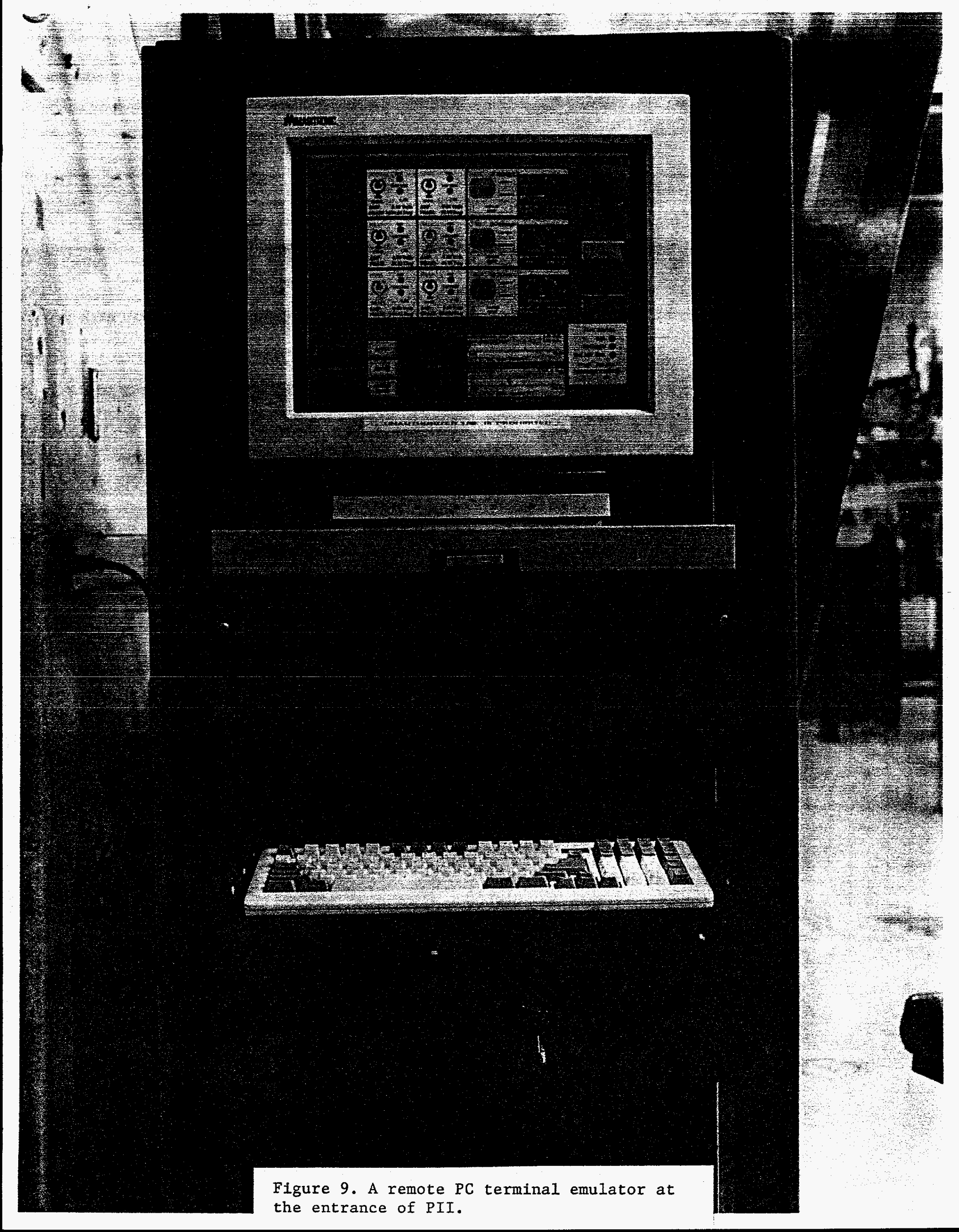




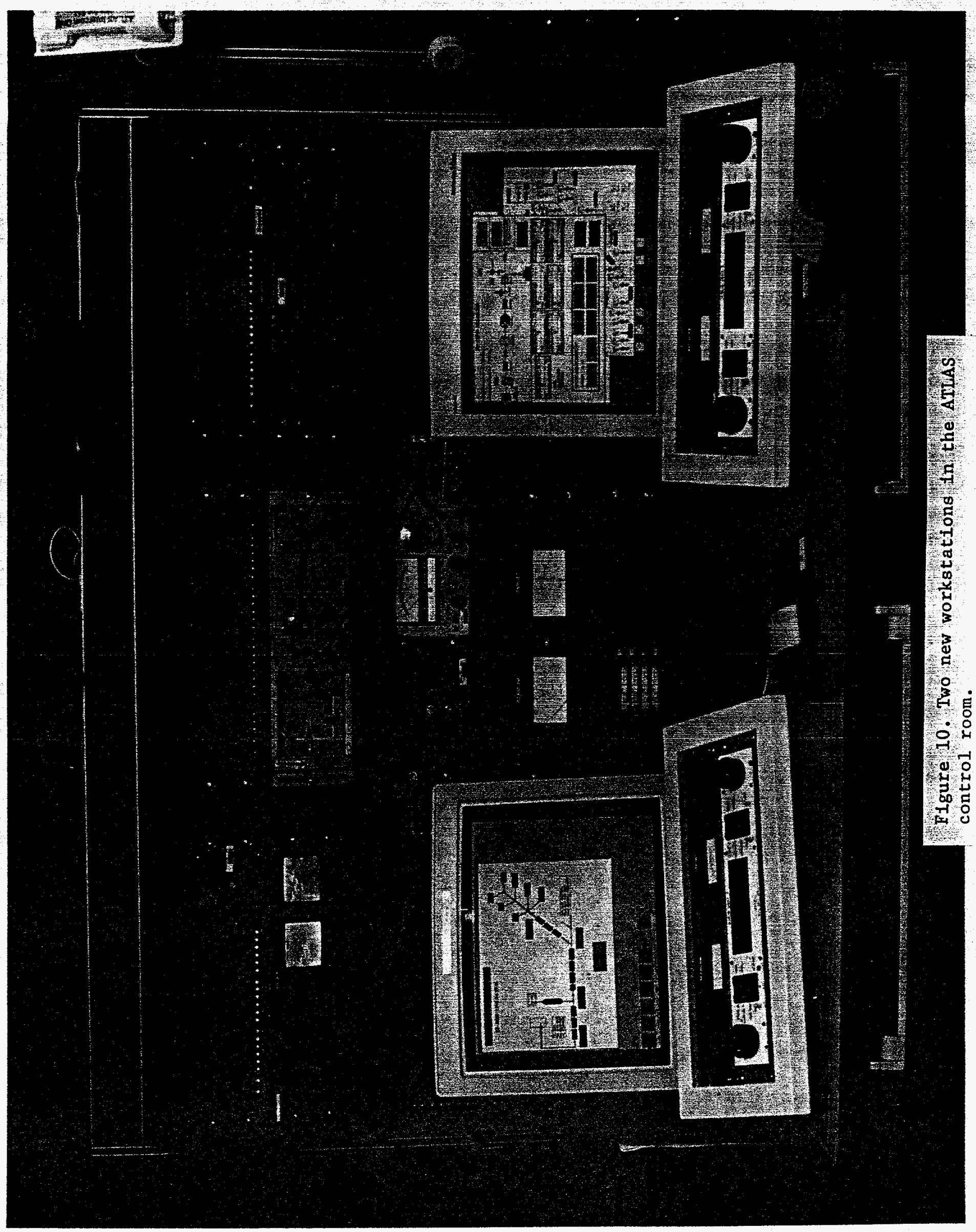




\section{Argonne Exotic Beam Laboratory}

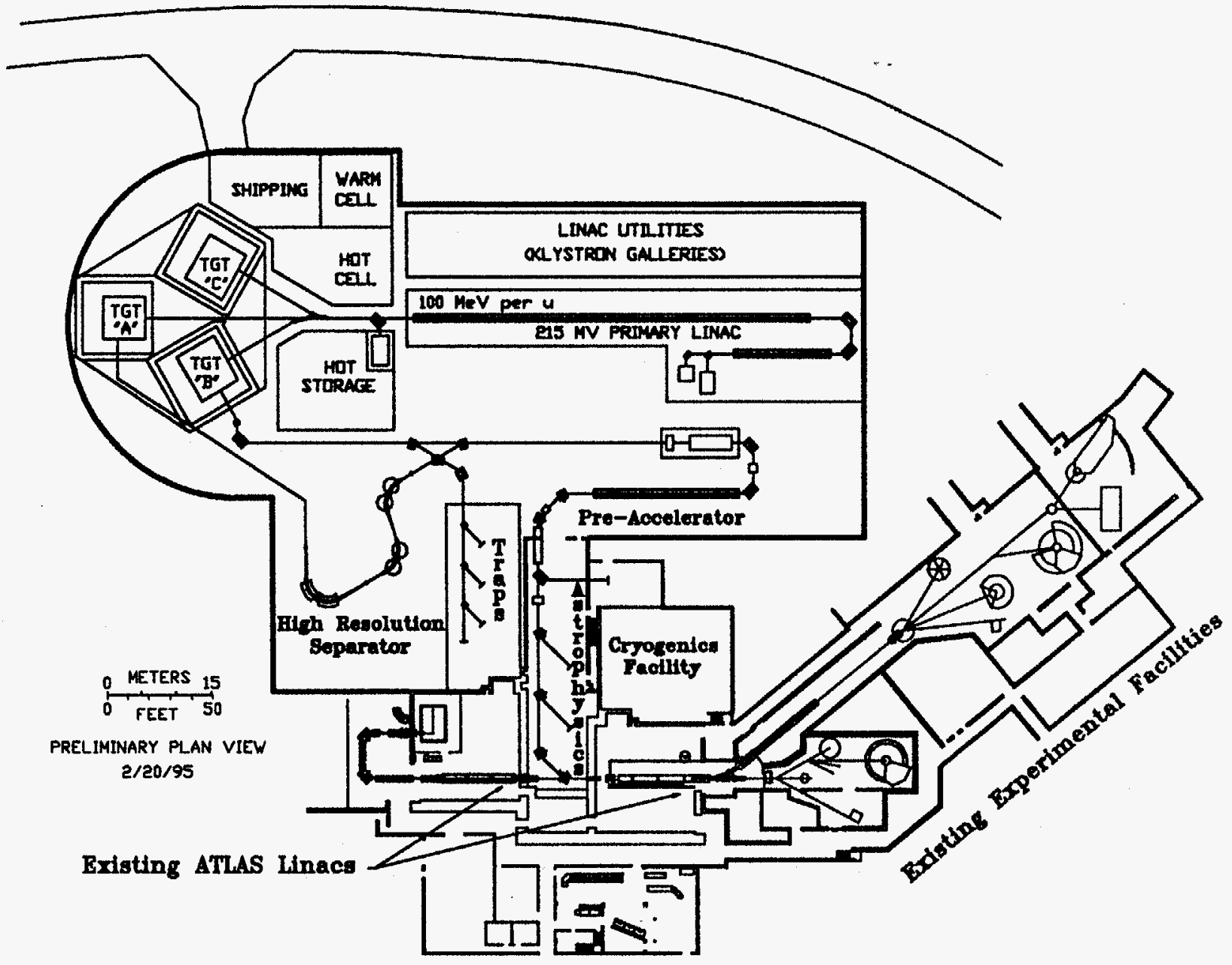

Fig. 11. A layout of the conceived Exotic Beam Laboratory. The lower section shows the existing ATLAS facility. 


\section{Heavy Ion Production Linac}

Concept for exotic isotope production

\section{MV Linac}

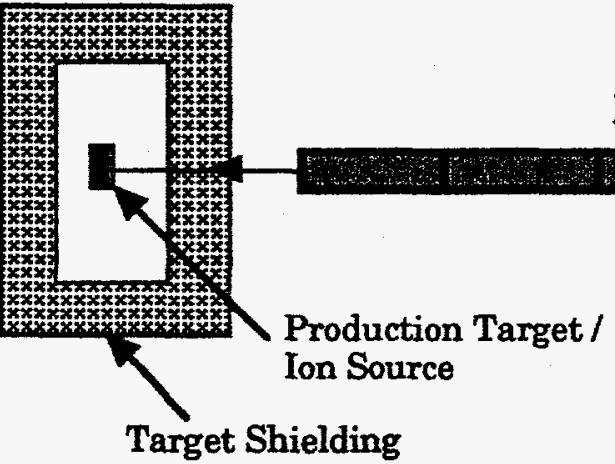

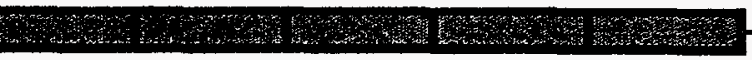

Target Shielding

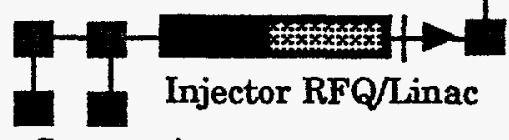

Ion Sources /

Light and Heavy Ion

\section{Parameters of the Production Linac}

Max Output Beam Energy:

Max Output Beam Power:

Typical Light Ions (multicusp ion source):

Typical Heary Ions (pulsed ECR ion source):

Typical Max. Light Ion Currents $9100 \mathrm{~kW}$ :

Typical Max. Heavy lon Currents $100 \mathrm{~kW}$ :

Typical Heavy Ion Source/Stripping Limits:
$100 \mathrm{MeV}$ per nucleon

$100 \mathrm{~kW}$

${ }^{1} \mathrm{H},{ }^{2} \mathrm{H},{ }^{4} \mathrm{He}$

$12 c^{2+, 6+, 16,18} \mathrm{o}^{3+, 8+, 20,22} \mathrm{Ne}^{4+, 10+, 36} \mathrm{Ar} 6+, 16+$

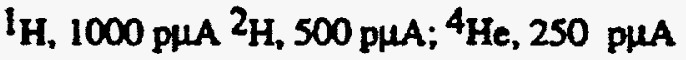

$18 \mathrm{O}^{8+}, 55 \mathrm{p \mu A}^{36} \mathrm{Ar}^{16+} .28 \mathrm{p \mu A}$

${ }^{18} \mathrm{O}^{8+}, 20 \mathrm{p \mu A}^{36} \mathrm{Ar}^{16+}, 3 \mathrm{p \mu A}$

Linac Speciflcations:

Injector RFQ/Linac

Main Linac

Duty Cycle

Input Power

Output Energy Variability

Controls
$5 \mathrm{MeV} / \mathrm{u}$ output @ $\mathrm{q} / \mathrm{m}=1 / 6,(30 \mathrm{MV})$

$100 \mathrm{MeV} / \mathrm{u}$ output $@ q / \mathrm{m}=8 / 18$, (215 MV)

$2 \%$ @ $120 \mathrm{~Hz}$

$1 \mathrm{MW}$

$15 \%$ increments

Pulse-pulse ion source and energy variation possible

Figure 12. Conceptual layout of the Production Linac, its ion sources and injector, and a simplified target cell. General specifications, typical beams and currents, and some linac parameters are listed under the figure. 


\section{Experiment at MSU}

\section{Off-line Gamma-spectra}

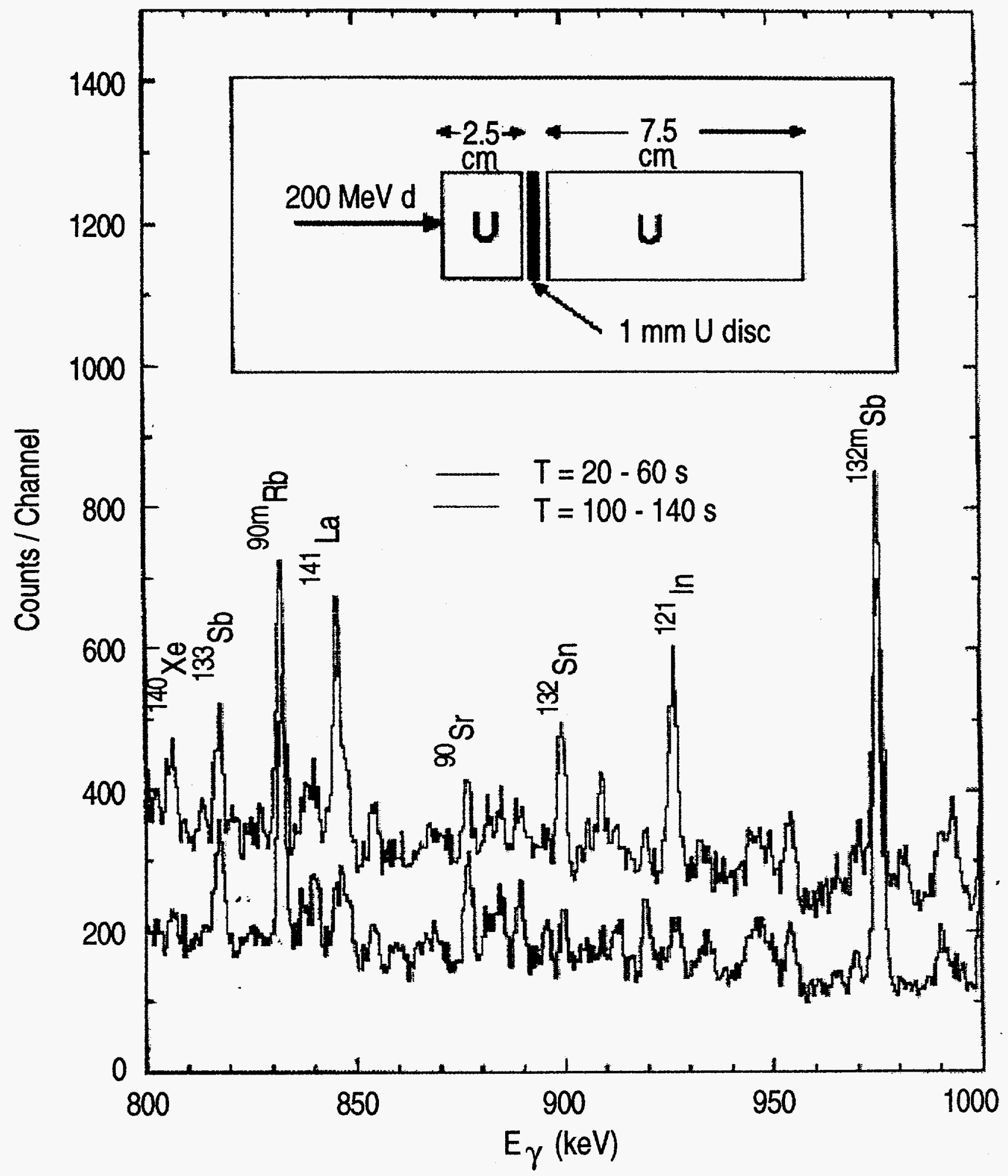

Figure 13. Portions of off-line gamma-ray spectra of a thin ${ }^{238} \mathrm{U}$ disc irradiated with neutrons produced from a $200 \mathrm{MeV}$ d beam stopping in a $2.5 \mathrm{~cm}$ thick $U$ piece. The spectra were measured with a $100 \% \mathrm{Ge}$ detector and the time intervals were chosen to maximize the yields of $132 \mathrm{Sn}$, which has a $40 \mathrm{~s}$ half-life. 


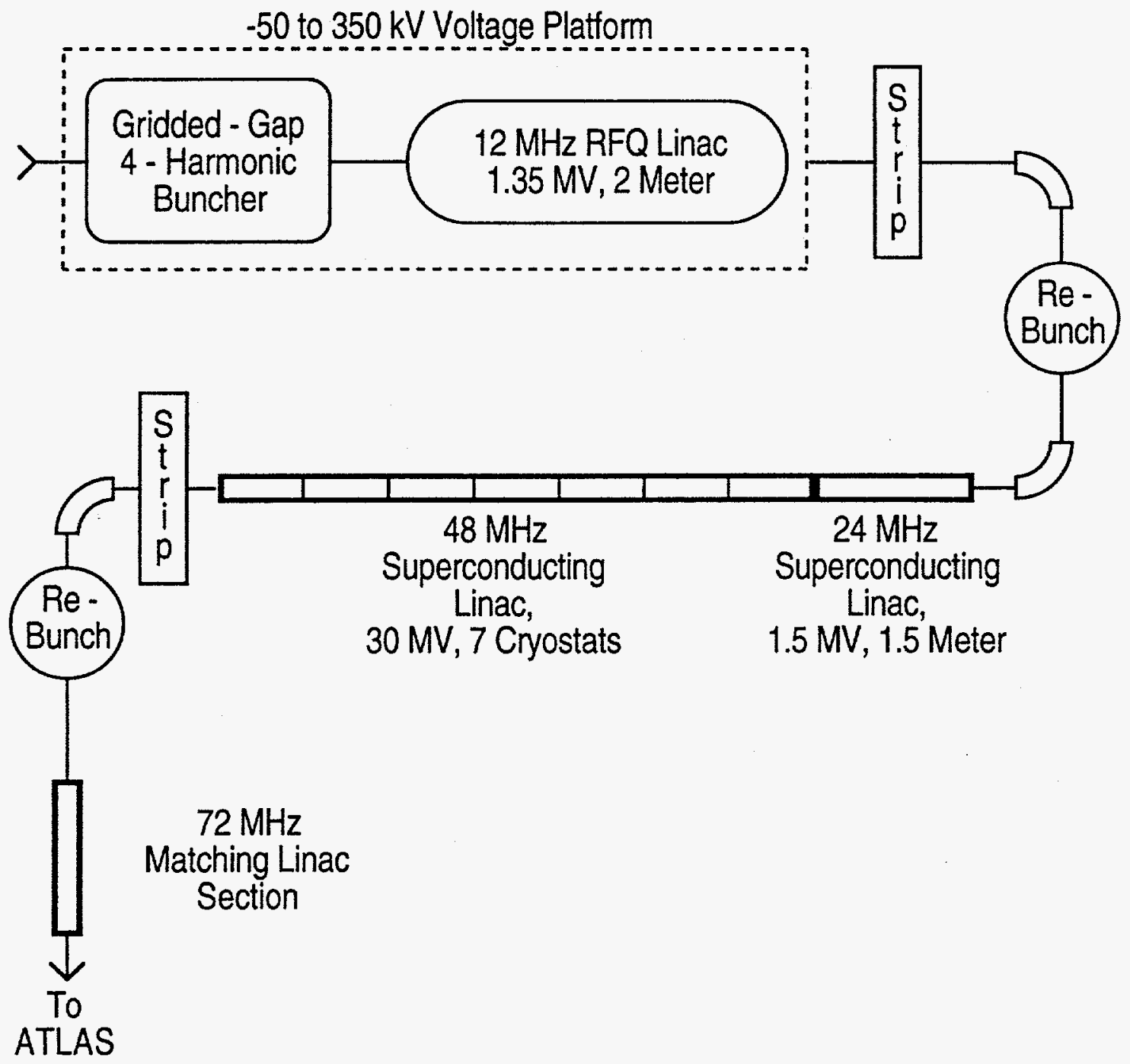

Figure 14. Block diagram showing the elements of the low-charge-state injector linac. 1 ions at $100 \mathrm{kV}$ are accelerated to energies of $1.2 \mathrm{MeV}$ per nucleon before entering the existing ATLAS heavy-ion accelerator system. The positions of the two stripping stages are indicated. Ions with mass less than $\sim 70$ do not require the first stripping. 


\begin{tabular}{|c|c|c|c|c|c|c|c|c|c|c|}
\hline & \multicolumn{9}{|c|}{ Worksheet for the Secondary Beam Accelerator for the Argonne Exotic Beam Laboratory } & \\
\hline & & & & & & & & & & \\
\hline \multicolumn{3}{|c|}{ Driver Accelerator: } & & \multicolumn{6}{|c|}{$200 \mathrm{MV}$ Linac, $q / \mathrm{m}=0.5,100 \mathrm{~kW}$ beam power, $120 \mathrm{~Hz}$} & \\
\hline & & & & & & & & & & \\
\hline \multicolumn{4}{|c|}{ Radioactive Beam Accelerator: } & & \multicolumn{2}{|c|}{${ }^{132} \mathrm{Sn}$ Example } & 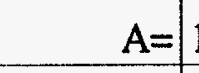 & 132 & & \\
\hline & & & & & & & & & & \\
\hline Voltage & & & & Accel. & & & & & & \\
\hline gain & $\mathrm{q}$ & T/A & velocity & length & efficiency & efficiency & intensity & intensity & Device: & Comments: \\
\hline \multirow[t]{2}{*}{ (MV) } & & $(\mathrm{MeV} / \mathrm{A})$ & $(\mathrm{v} / \mathrm{c})$ & (m) & (this step) & (cumulat.) & (ions/sec) & (part. na) & & \\
\hline & & & & & & & $1.0 \mathrm{E}+13$ & & primary production rate & $100 \mathrm{~g} / \mathrm{cm}^{2} \mathrm{UC}$ target \\
\hline \multirow[t]{2}{*}{0.1} & 1 & 0.0008 & 0.0013 & & 0.03 & 0.030 & $3.0 \mathrm{E}+11$ & 50.0 & ion source \& release & $4 \pi \mathrm{mm}-\mathrm{mr}$ \\
\hline & & & & & 0.80 & 0.024 & $2.4 \mathrm{E}+11$ & 40.0 & isobar separation & resolution $\sim 30,000$ \\
\hline \multirow[t]{2}{*}{0.3} & 1 & 0.003 & 0.003 & 1.0 & 1.00 & 0.024 & $2.4 \mathrm{E}+11$ & 40.0 & onto HV platform & \\
\hline & & & & & 0.65 & 0.016 & $1.6 \mathrm{E}+11$ & 26.0 & prebunch/rebunch & \\
\hline 1.0 & 1 & 0.011 & 0.005 & 2.0 & 0.95 & 0.015 & $1.5 \mathrm{E}+11$ & 24.7 & RFQ on HV platform & $12 \mathrm{MHz}$ RFQ \\
\hline-0.3 & 1 & 0.008 & 0.004 & 1.0 & 1.00 & 0.015 & $1.5 \mathrm{E}+11$ & 24.7 & leave HV platform & \\
\hline 0.0 & 2 & 0.008 & 0.004 & & 0.40 & 0.006 & $5.9 \mathrm{E}+10$ & 9.9 & strip and rebunch & Gas stripper \\
\hline 2.0 & 2 & 0.039 & 0.009 & 2.0 & 0.95 & 0.006 & $5.6 \mathrm{E}+10$ & 9.4 & $24 \mathrm{MHz}$ linac & SC folded resonator \\
\hline \multirow{3}{*}{30.0} & 2 & 0.493 & 0.033 & 15.0 & 0.95 & 0.005 & $5.4 \mathrm{E}+10$ & 8.9 & $48 \mathrm{MHz}$ linac & PII-type, 4 gap \\
\hline & 20 & 0.493 & 0.033 & 1.0 & 0.20 & 0.0011 & $1.1 \mathrm{E}+10$ & 1.8 & strip to $\mathrm{q} / \mathrm{m}=0.15$ & Foil stripper \\
\hline & 20 & 0.493 & 0.033 & 2.0 & 1.00 & 0.0011 & $1.1 \mathrm{E}+10$ & 1.8 & rebunch & \\
\hline 4.0 & 20 & 1.099 & 0.049 & 3.0 & 0.95 & 0.0010 & $1.0 \mathrm{E}+10$ & 1.7 & $72 \mathrm{MHz}$ matching linac & PII-type, 4-gap \\
\hline 40.0 & 20 & 7.160 & 0.123 & 25.0 & 0.90 & 0.0009 & $9.1 \mathrm{E}+09$ & 1.5 & out of ATLAS & existing accelerator \\
\hline
\end{tabular}

Fig. 15. Worksheet illustrating a scenario for post-acceleration of ${ }^{132} \mathrm{Sn}$. 